\title{
Molecular Diagnostics in Transfusion Medicine: In Capillary, on a Chip, in Silico, or in Flight?
}

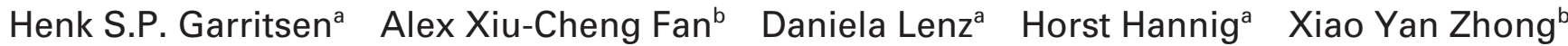 \\ Robert Geffers $^{c}$ Werner Lindenmaier ${ }^{c} \quad$ Kurt E.J. Dittmar ${ }^{c}$ Bernhard Wörmann ${ }^{a}$ \\ a Institute for Clinical Transfusion Medicine, Department of Hematology/Oncology Städtisches Klinikum Braunschweig gGmbH, \\ Braunschweig, Germany \\ ${ }^{\mathrm{b}}$ Laboratory for Prenatal Medicine and Gynecologic Oncology, Women's Hospital / Department Research, University of Basel, Switzerland \\ ${ }^{c}$ Department of Molecular Biotechnology, Helmholtz Center for Infectious Disease Research (HZI) Braunschweig, Germany
}

\section{Key Words}

Blood groups - Blood transfusion - Dendritic cells .

Genome amplification technology - HLA .

Molecular blood group typing - NAT · PCR · Platelets .

Real-time PCR · MALDI-TOF MS

\section{Summary}

Serology, defined as antibody-based diagnostics, has been regarded as the diagnostic gold standard in transfusion medicine. Nowadays however the impact of molecular diagnostics in transfusion medicine is rapidly growing. Molecular diagnostics can improve tissue typing (HLA typing), increase safety of blood products (NAT testing of infectious diseases), and enable blood group typing in difficult situations (after transfusion of blood products or prenatal non-invasive RhD typing). Most of the molecular testing involves the determination of the presence of single nucleotide polymorphisms (SNPs). Antigens (e.g. blood group antigens) mostly result from single nucleotide differences in critical positions. However, most blood group systems cannot be determined by looking at a single SNP. To identify members of a blood group system a number of critical SNPs have to be taken into account. The platforms which are currently used to perform molecular diagnostics are mostly gel-based, requiring time-consuming multiple manual steps. To implement molecular methods in transfusion medicine in the future the development of higher-throughput SNP genotyping non-gelbased platforms which allow a rapid, cost-effective screening are essential. Because of its potential for automation, high throughput and cost effectiveness the special focus of this paper is a relative new technique: SNP genotyping by MALDI-TOF MS analysis.

\author{
Schlüsselwörter \\ Blutgruppen - Bluttransfusion - Dendritische Zellen . \\ Genomamplifikationstechnologie - HLA . \\ Molekulare Blutgruppentypisierung · NAT · PCR · \\ Thrombozyten · Real-time-PCR · MALDI-TOF MS
}

\section{Zusammenfassung}

Serologie, definiert als antikörperbasierte Diagnostik, wurde bisher in der Transfusionsmedizin als diagnostisches Goldstandard betrachtet. Heutzutage wächst aber der Einfluss der Molekulardiagnostik in der Transfusionsmedizin rapide. Molekulare Diagnostik kann die Gewebetypisierung (HLA-Typisierung) optimieren, die Sicherheit von Blutprodukten vergrößern (NAT-Test von infektiösen Krankheiten) und Blutgruppenbestimmungen in schwierigen Situationen (nach Transfusion von Blutprodukten oder pränatale Rhesus-Bestimmungen) erleichtern. Meistens basiert die Molekulare Diagnostik auf der Bestimmung der Anwesenheit von Single Nucleotide Polymorphisms (SNPs). Antigene (z.B. Blutgruppen-Antigene) resultieren meistens aus der Anwesenheit von unterschiedlichen Nukleotiden an kritischen Positionen. Bei der molekularen Bestimmung der meisten Blutgruppensysteme sind jedoch mehrere SNPs relevant. Zur Identifizierung verschiedener Spezifitäten eines Blutgruppensystems muss man in der Regel mehrere kritische SNPs betrachten. Die Systeme, die zur Zeit für molekulare Diagnostik genutzt werden, sind meistens gelbasiert, dies erfordert zeitintensive manuelle Schritte. Um molekulare Methoden der Transfusionsmedizin in der Zukunft einzusetzen, benötigen wir die Entwicklung von HochdurchsatzSystemen, die nicht gelbasiert sind und eine schnelle kosteneffektive Analyse ermöglichen. Wegen seiner Möglichkeiten für Automation, Hochdurchsatz und Kosteneffizienz wird eine relativ neue Technik - SNP-Genotypisierung durch MALDI-TOF-MS-Analyse - in den Mittelpunkt dieses Artikels gestellt.

\begin{tabular}{|c|c|}
\hline KARGER & (c) 2009 S. Karger GmbH, Freiburg \\
\hline $\begin{array}{l}\text { Fax +49 } 7614520714 \\
\text { Information@Karger.de } \\
\text { www.karger.com }\end{array}$ & $\begin{array}{l}\text { Accessible online at: } \\
\text { www.karger.com/tmh }\end{array}$ \\
\hline
\end{tabular}




\section{Introduction}

With the emerging technology of genetic diagnosis and the genetic characterization of polymorphisms a whole new area opens for clinical medicine and in particular for transfusion medicine [1-4]. Whereas molecular characterization was previously laborious and time-consuming, the introduction of automation reshaped the field. From the extraction of DNA or RNA to final data analysis new instruments and software enable the molecular identification of large amounts of samples within limited time. These developments have greatly improved the clinical utility of molecular techniques. However, not only innovative molecular diagnostic techniques and software programs have shaped the applications in transfusion medicine. At least in Germany, legislature prescribing the nucleic acid testing for HIV and HCV for all donated blood products has pushed forward the development of highthroughput molecular diagnostic instruments. The goal of this review is to give an overview of different qualitative and quantitative molecular diagnostic options with a special focus on a relatively new promising technique: MALDI-TOF MS genotyping.

\section{In Capillary 1}

In the early 1990s Carl Wittwer started to work on systems which were able to speed up DNA amplification reactions. The idea was to develop a rapid thermal cycling system by using thin-walled glass capillary test tubes (to increase the surface-to-volume ratio) and hot air to increase the speed of the PCR cycling reaction. The resulting air thermocycler instrument matched the speed of biochemical reactions and was 10 times faster than commercially available instruments. Through further developments in software, hardware, and chemistries the next goal became within reach: amplification and sensitive detection of PCR products in the same instrument [5-8]. Thus, there is no need to open tubes or capillaries after the PCR amplification process. This reduces the risk of contamination and pipetting errors, and because gel electrophoresis as detection step is eliminated the time for detection of PCR products is also minimized. Advantages in chemistry of fluorescent dyes (e.g. SYBR-Green) or use of fluorescencelabelled oligonucleotides facilitated routine implementation of molecular diagnostic systems. SYBR-Green has a strong increase in fluorescence when it binds to double-stranded DNA (e.g. PCR products). Therefore, the detection sensitivity is increased. But also the possibilities to label oligonucleotides fluorescently, e.g. by FRET (fluorescence resonance energy transfer), enable a sensitive and specific detection. FRET probes are a pair of fluorescent probes placed in close proximity. The emission spectrum of one fluorophore overlaps significantly with the excitation spectrum of the other. During FRET, the donor fluorophore excited by a light source trans- fers its energy to an acceptor fluorophore when positioned in the direct vicinity of the former. The acceptor fluorophore emits light of a longer wavelength which is detected in specific channels. The light source cannot excite the acceptor dye.

Monitoring the amount of fluorescence during each PCR cycle is defined as real-time PCR. There is a direct relation between the starting amount of DNA (template DNA) and the number of PCR cycles which are needed to obtain a predefined fluorescence intensity with a certain number of PCR products. If you have a large quantity of template DNA you need less PCR cycles to reach this fluorescence threshold than with a small amount of template DNA. In other words: the threshold cycle is indicative for the amount of starting (template) DNA. This method allows a (semi-)quantification of starting material. Parallel to the described capillary system, microtiter plate systems have been developed which have similar advantages and possibilities. Variation in fluorescence chemistry and detection filter combinations allow multiplex PCR (analyzing multiple gene sequences in the same PCR reaction). However, multiplexing in real-time PCR is limited to 2-3 different gene sequences.

Due to reproducibility, sensitivity and quantification, realtime PCR has become an accepted method to detect viral contamination in blood products [9-14]. Real-time PCR is fast but expensive. Therefore, real-time PCR is mostly used to quantify the viral load in studies and only to a limited extent in routine applications (e.g. NAT testing for HCV and HIV).

\section{In Capillary 2}

DNA sequencing using capillary electrophoresis succeeded the generation of automated gel-based DNA sequencers in the middle of the 1990s [15, 16]. Fluorescently labelled DNA fragments generated in enzymatic sequencing reactions are rapidly separated by capillary electrophoresis and detected. They are mostly based on a modified Sanger sequencing reaction where fluorescent fragments are at random generated in PCR reaction (cycle sequencing). In this PCR reaction only a small percentage of the nucleotides in the reaction mix is labelled with fluorescent dyes. Each nucleotide (guanine, cytosine, thymidine and adenosine) bears its own fluorescence dye that fluoresce at different wavelength of the spectrum. Furthermore, these fluorescent nucleotides are chemically modified and consist of didesoxyriboses. Incorporation of the fluorescent nucleotide leads to a chain demolition (cycle sequencing). Because it is an at-random process when and which length a fluorescence-labelled nucleotide is incorporated after a fixed number of PCR cycles, statistically all nucleotide positions are labelled and the PCR tube contains thousands of fragments with a different length and a specific fluorescently labelled dye at the end. The capillary electrophoresis DNA sequencer is used to automatically separate these fragments (a short fragment will run faster than a longer fragment) and 
Fig. 1. MT-DNA

haplotype determination using capillary electrophoresis and a multiplex

primer extension reaction. A SNaPshot assay was developed which incorporated multiple mtDNA-SNPs to identify common European mtDNAHaplotypes (in this

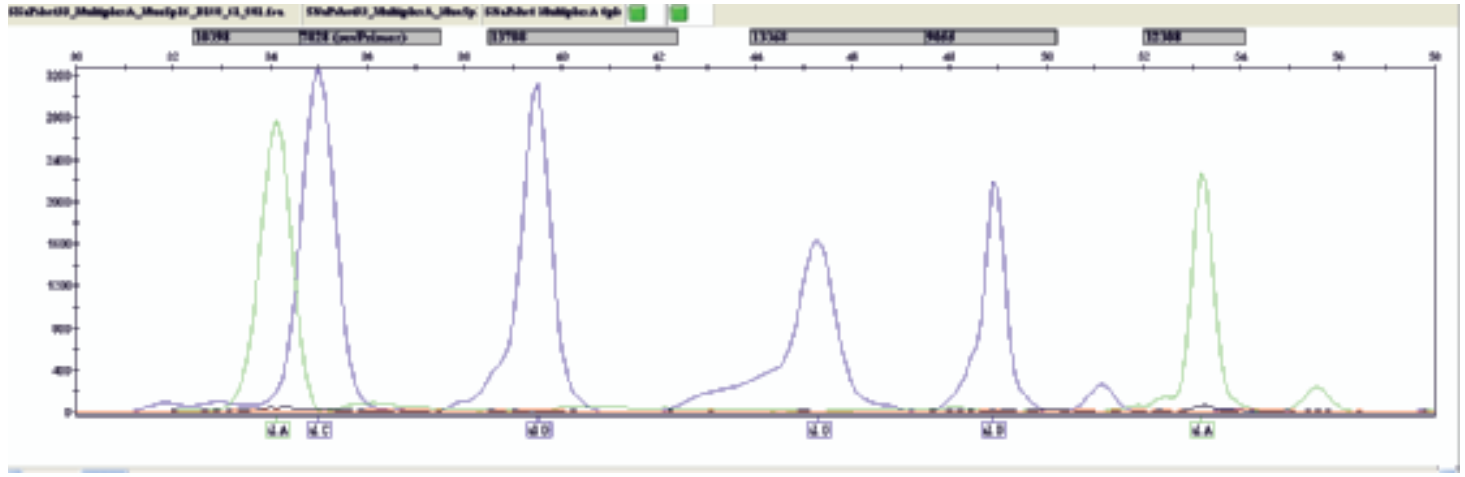
case mtDNA-Haplotype H) The informative SNPs for Haplotype H are 7028 C,9055 G, 10398 A, 12308 G, and 13368 G which can be identified unambiguously on the electropherogram.

analyzed. Cycle sequencing using capillary electrophoresis has become a standard method in transfusion medicine, especially for high-resolution HLA typing. The method can be modified for high throughput by simply increasing the number of sequencing capillaries which can be run in parallel.

For the analysis of predefined SNPs, DNA sequencing using cycle sequencing is not necessary and more and more replaced by other techniques. In the majority of cases these techniques are variations of a technique called minisequencing. In this technique a single-stranded DNA fragment which has the complementary sequence of the region of interest direct next to the SNP position to be tested is incorporated in the PCR mix together with fluorescence-labelled didesoxyribose nucleotides. A primer extension will take place during the PCR reaction, but only until a fluorescence-labelled didesoxyribose nucleotide is incorporated; then the reaction is stopped (minisequencing). The fluorescent labelling is indicative for the nucleotide on the SNP position. By varying the length of the single-stranded DNA fragment next to SNP position it is possible to analyze different SNPs in one PCR reaction (multiplex PCR) using capillary electrophoresis and a fluorescence detection unit. An example of such an minisequencing assay is given in figure 1 where we analyzed multiple mtDNA (mitochondrial DNA) haplotype-specific SNPs in a single reaction (SNaPshot Assay) [17-23].

This SNaPshot was carried out in multiplex using the SNaPshot multiplex kit (Applied Biosystems, Foster City, CA, USA). The reaction involves the extension of an oligonucleotide probe designed to lie adjacent to the SNP of interest by one of four fluorescently labelled dideoxynucleotides complementary to the base found at the SNP site. The oligonucleotides probes within one multiplex reaction are designed to be of different lengths by addition of neutral sequence so that when they are separated by capillary electrophoresis only one product will be seen within a size range. The size range of the primer can vary between 15 and 30 nucleotides. For successful multiplexing it is recommended that one uses primers different by sets of 4 nucleotides. Theoretically 5 different SNPs can be run in one assay. However, there is a second level of multiplexing: you can run together an assay for an $\mathrm{A} / \mathrm{G}$ polymorphism and a $\mathrm{C} / \mathrm{T}$ polymorphism even if the primers are the same lengths. This theoretically doubles the number of SNPs run in one assay to 10 different SNPs. Extreme caution have to be taken when designing primers for multiplex assays. If one is targeting a C/T polymorphism on the forward strand, it will give you an $\mathrm{A} / \mathrm{G}$ polymorphism on the reverse strand using a reverse probe. It is advisable to run an assay on its own before multiplexing it.

Following the SNaPshot reaction, the mixture is digested with shrimp alkaline phosphatase to prevent any further primer extension by eliminating non-incorporated dideoxyribonucleotide triphosphates (ddNTPs). The fluorescently extended probes are then separated on a ABI 3130 capillary electrophoresis system (Applied Biosystems) in the presence of a fluorescence-labelled size standard. Using this approach and 10 SNPs indicative for mtDNA haplotypes frequent in Caucasians as published by Wiesbauer et al. [24], we analyzed 800 platelet apheresis donors.

Again as in real-time PCR separation and analysis is in one instrument although the amplification and purification of the PCR product is separate but can be automated to a large extent.

A new generation of powerful non-gel-based DNA sequencers are currently introduced. It will however take some years before the capillary DNA sequencer generation is replaced by them.

\section{On a Chip}

Since micro-arrays were first described 13 years ago [25], they have evolved into a standard experimental technology that has had a profound impact in molecular biology. Especially micro-arrays with high numbers of features are still relatively expensive. Global transcription patterns as well as nucleotide polymorphisms can now be readily evaluated using DNA micro-arrays. Micro-arrays exploit preferential binding 
of DNA or RNA to their complementary single-stranded sequences. A micro-array chip consists of thousands of singlestranded DNA molecules attached in fixed positions onto a solid silicate surface. Usually the micro-array chip is incubated with a biological extract (mRNA or cDNA) that is labelled with a fluorescent dye. Thus a single micro-array experiment produces thousands of data points, each of which is a measure of the quantity of fluorescent label, bound at a feature on the micro-array chip. These fluorescent intensities are determined using a fluorescence reader from which the concentration of mRNA/cDNA molecules are inferred. Tens of thousands of features can be fixed to a single micro-array chip, thus providing an opportunity to quantify thousands of gene transcripts, actually the entire human transcriptome, in a single experiment. Knowing the presence or absence of transcripts for all the genes in the genome at a particular moment and their changes relative to some reference state can be an extremely valuable information, and these detailed transcriptomic portraits provide hitherto unimaginable insights into the regulation of biological processes in individual cells, normal tissues, or tumors. The number of applications of micro-arrays has increased dramatically.

In addition to assessing mRNA abundancy, micro-arrays have also been applied for the quantification of DNA copy number, DNA sequence variations and protein-binding sites in a genome. Technological advancement ensures that higher numbers of features can be spotted on micro-arrays. The applications of chip arrays in transfusion medicine are limited. There was an approach to perform high-resolution HLA typing using micro-array technology. This approach was not successful due to technical problems with the micro-arrays. One of the main problems is that almost all SNPs relevant for highresolution HLA typing are more or less concentrated on a relative short stretch of chromosome 6 instead of being dispersed over the complete genome. Furthermore, due to intense HLA genotyping novel SNPs are detected every month, leading to continuous redesign of the micro-array. Moreover HLA ambiguities caused analyzing problems in silico.

A current project is the BloodGen project supported by the EU [26-28]. In a subproject a number of research groups have joint to implement immunohematologically relevant SNPs onto a DNA micro-array. Because the number of data points are significantly lower than needed in HLA high-resolution analysis and the relevant SNPs are dispersed more equally over the complete genome, this project has been successful.

We applied micro-array technology and in silico analysis to investigate potential differences in global transcription patterns comparing cultivation and maturation of human genetically modified and non-modified mature dendritic cells. Micro-arrays allow us to monitor gene expression profiles of thousands of genes in a single experiment. An example is given in figure 2 where we concentrated on transcriptional changes of immunorelevant genes in genetically modified and non-modified mature dendritic cells.

\section{In Silico}

The terminology 'in silico' refers to the processing and modeling of huge amounts of physical data of biological origin by computers. Computer chips are mostly made of the element silicium, therefore: in silico. This process of computational analysis of biological information gained more and more importance through the availability of high-throughput molecular diagnostic methods like automated sequencing and most of all through the development and availability of micro-arrays.

Scientists are encouraged to submit their raw data obtained with these technologies in public data repositories. These repositories contain a rapidly expanding collection of gene expression data of numerous cell types (in numerous experimental conditions in several species) which form an excellent resource for in silico evaluation.

Micro-arrays produce transcriptional data and indirect measure of expression (translational data). Processing of these data in biologically meaningful units is not a trivial task. Complex processing, normalization, and statistical analysis are required to obtain even the most basic information from these data. Numerous bioinformatic statistical and machinelearning methods have been applied to micro-array data. The goal of micro-array data preprocessing is to transform detected fluorescent signal values into biological meaningful measurements. Unfortunately, the relationship between the fluorescence intensity and the abundance of a given RNA/DNA molecule is not straightforward.

\section{In Flight}

Recently, MALDI-TOF MS was introduced for molecular diagnostics. It offers a solution for high-throughput qualitative and quantitative analysis of up to 36-40 multiple SNPs in a single reaction.

MALDI-TOF MS stands for matrix-assisted laser desorption/ ionization time of flight mass spectrometry. The process consists of two parts:

i) Laser-induced desorption/ionization of analyte/matrix molecules (MALDI).

ii) Separation and analysis of different biomolecules based on intrinsic physical properties (TOF).

\section{Laser-Induced Desorption/Ionization of Analyte/}

\section{Matrix Molecules}

In preparation for MALDI-TOF MS SNP analysis, oligonucleotides can be generated using a minisequencing reaction without the need to label any nucleotides. PCR is performed either in multi- or uniplex format, followed by a Thermo Sequenase ${ }^{\mathrm{TM}}$ sequencing reaction using an oligonucleotide bound directly adjacent to each SNP and stop mixes containing cocktails of ddNTPs. Adding an anion exchange resin 


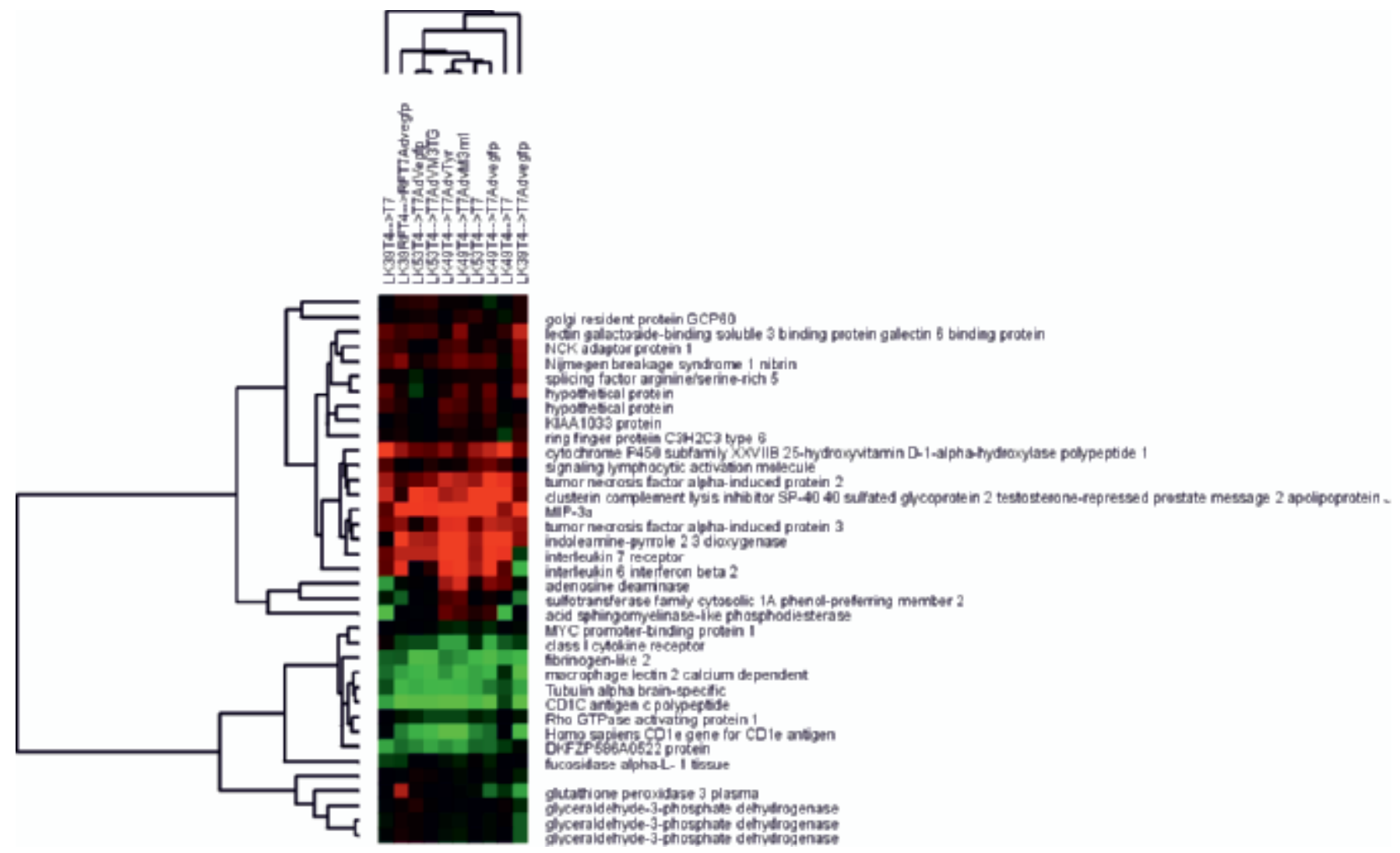

Fig. 2. cDNA arrays data for comparing gene expressions from human genetically modified and non-modified dendritic cells (DCs). Mature DC's from three different donors (LK39, LK49, LK53) or modified culture conditions (RF) were compared with genetically modified mature DC's using different adenoviral vectors (AdVegfp, AdVM3TG,AdVTyreG, AdVM3m1eG). Data for selected immunorelevant genes are shown here. They compare gene expression of immature DC on day 4 of cultivation to DC gene expression of mature DC on day 7. Overexpression is labelled green, downregulation is colored red. Cluster analysis shows that the gene expression pattern of the genes shown is independent from the genetic modification.

removes adduct-forming ions. $15 \mathrm{nl}$ of the extension cocktail is spotted onto a silica-based chip array containing 384 matrix pads using a nanoliter plotting robot. Choosing the right matrix is essential for the success of the reaction. At this moment 3-hydroxypicolinic acid (3-HPA) is in use as a matrix for DNA/RNA analysis. Although the ratio matrix:analyte is approximately 1:1,000, the matrix is essential to support the laser light-induced desorption and ionization of the analyte (DNA). The silica chip array is placed into the mass spectrometer, and a laser (usually N2-laser with $337 \mathrm{~nm}$ wavelength) fires 3-5 ns pulses of approximately $100 \mu \mathrm{J}$ to each matrix pad to initiate the desorption/ionization process of the DNA analyte.

\section{Separation and Analysis of Different Biomolecules Based on Intrinsic Physical Properties (TOF)}

By applying an electrical charge the intact ionized analytes are accelerated in a vacuum detector chamber and are attracted to a detector. The time taken by each particle to fly to the detector (time of flight) is characteristic for each analyte. This time is inversely related to the velocity, which in turn is proportional to the mass/charge $(\mathrm{m} / \mathrm{z}$ ) ratio of a flying particle (e.g. DNA fragment). The time of flight is a specific characteristic of each
DNA fragment since the $\mathrm{m} / \mathrm{z}$ ratio is an intrinsic property of the DNA and depends only on base composition. In the case of SNP analysis the mass differences of the nucleotide in the polymorphic position is sufficient to discriminate an A, T, G or C (e.g. desoxyadenosine: $313 \mathrm{Da}$, desoxythymidine: 304 $\mathrm{Da}$, desoxyguanosine: $329 \mathrm{Da}$ and desoxycytosine: $289 \mathrm{Da}$ ). These small differences in molecular mass result in different peak positions. This situation allows us to discriminate DNA fragments which differ in only one base (SNPs) and, by specific design of the size of the DNA fragments, to test multiple SNPs in one reaction.

Development of powerful software enables the automated analysis of generated MALDI-TOF MS spectra, with the possibility to assign these spectra to different genotypes.

In our group, MALDI-TOF MS has been used successfully for genotyping single fetal nucleotide polymorphisms in maternal blood for non-invasive prenatal diagnosis of genetic diseases [29-31]. We applied this technique also for the investigation of relevant SNPs for platelet antigens (HPA1-5, HPA15) and relevant mtDNA polymorphisms in the hypervariable regions (HV I, HV II, and HV III) $[32,33]$ in a multiplex assay. An example is shown in figure 3. 
Fig. 3. Mass spectra of multiplex PCR MALDI-TOF data (MassArray Iplex primer extension system ) from DNA of a platelet-apheresis donor (donor 89) to identify relevant platelet antigens (HPA-1 to 5 and HPA-15) are shown. The peaks corresponding to the HPA alleles are indicated with colors (turkish blue for HPA-1, blue for HPA-2, green for HPA-3, red for HPA-4, gray for HPA-5 and pink for HPA-15). HPA genotype of this donor: HPA 1a/b, 2a/a, 3a/b, 4a/a, 5/a, 15a/b.

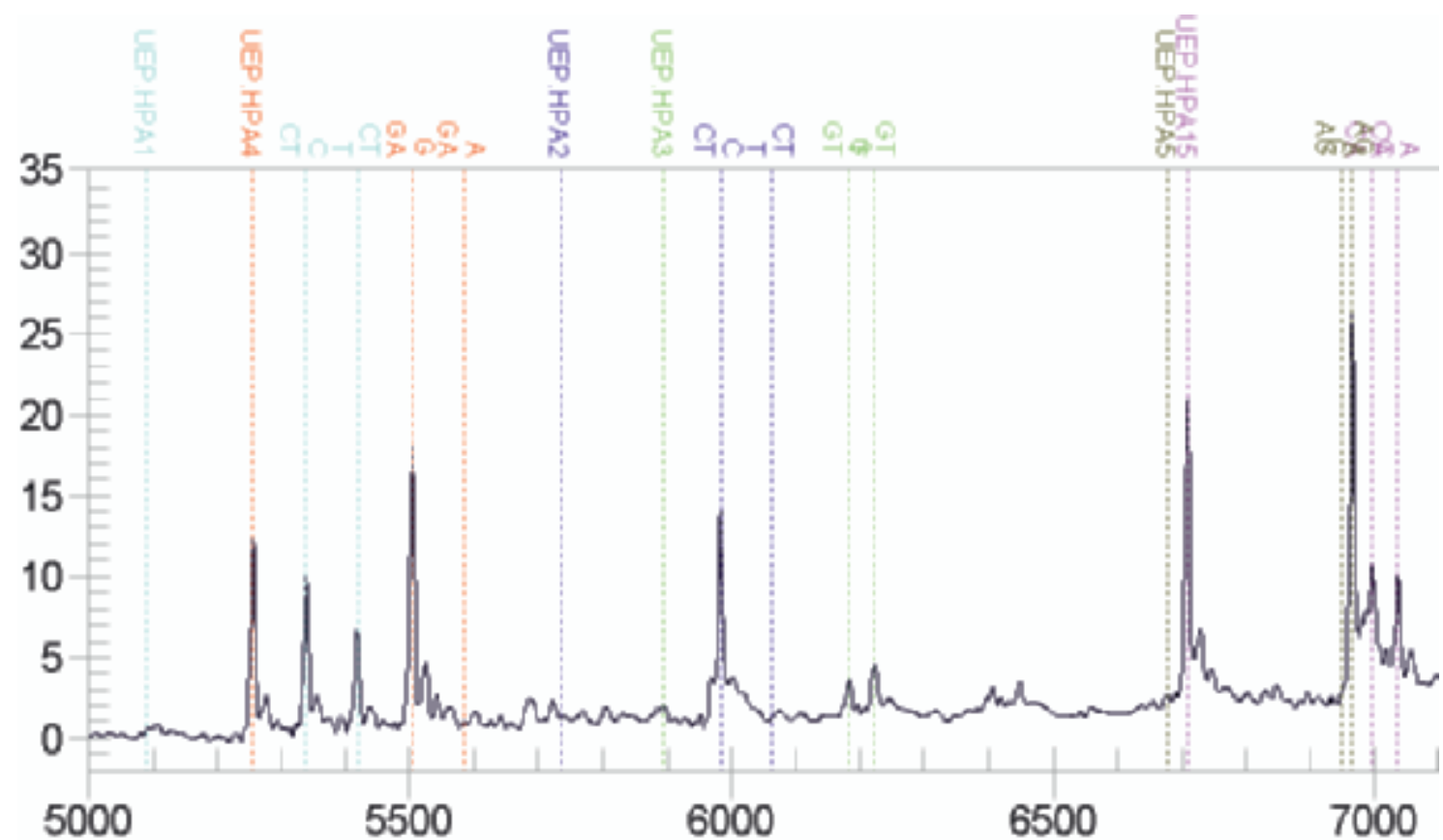

\section{Discussion}

The different molecular approaches presented in this paper show the rapid transition from gel-based systems to alternative systems. As to the applications which are going to be widely used, we feel that genotyping assays (SNP analysis) and DNA sequencing (e.g. HLA) are most important for transfusion medicine.

Real-time PCR systems offer a good sensitivity and accuracy of gene expression quantification but are suitable only to a limited extent to perform multiplex PCR reactions. Also their ability to handle a large number of samples is limited.

Extended gene arrays which offer the possibility of monitoring the complete transcriptome will only be of limited value in transfusion medicine: either to aid in the development and quality control of new cellular blood products as demonstrated in figure 2, or to be used in the implementation of new materials and manufacturing procedures. They are of significance rather in answering experimental clinical questions. The comparatively high costs of the gene arrays and instrumentation needed are also a disadvantage for routine application in transfusion medicine.

Gene arrays focusing on a predefined limited number of SNPs and therefore producing a limited number of data points will certainly have their place in transfusion medicine diagnostics. One of their disadvantages is that once produced they are relatively static. New informative SNPs can only be added to the new version of the assay. With regard to cost effectiveness, they certainly will be compatible.
Sanger sequencing combined with capillary electrophoresis will certainly be the standard for the next years as to DNA sequencing. The number of samples needed to be sequenced are limited in transfusion medicine, and DNA sequencing is mainly focused in tissue typing for stem cell transplantation. As shown in this paper, capillary electrophoresis can be combined with minisequencing reactions using fluorescence-labelled nucleotides. Currently theoretically 10 different SNPs can be analyzed in one multiplex PCR reaction. The system is fully automatable.

MALDI-TOF MS is a new technology for molecular diagnostics. It was first introduced as tool of choice in proteomics applications. In 1995 Tang et al. [34] demonstrated its usefulness in DNA analysis. Three years later methods for RNA applications using MALDI-TOF MS were published [35]. Although the whole process from sample preparation to automated analysis takes $8-9 \mathrm{~h}$ yet, we feel that we are still at the beginning of the clinical application of this technique. In contrast to the above mentioned techniques for SNP genotyping, with MALDI-TOF MS a sample throughput high enough for reliable analysis can be achieved, and MALDI-TOF MS does not rely on indirect detection reactions, involving specific nucleic acid labelling or hybridization steps. By measuring molecular mass, a direct physical property of the analyte, MALDI-TOF MS is not susceptive to background problems resulting from hybridization-based detection reactions.

The minimal amount of sample $(15 \mathrm{nl})$ underscores the potential for cost reduction. On the other hand, it requires purified samples free of ions and other impurities, increasing technical time, and sample processing costs. High cost efficiency at medium levels of multiplexing, high sample throughput, and 
the possibility to incorporate a high level of laboratory automation will make this procedure a serious competitor in molecular diagnostics. Due to the current high instrument costs, MALDI-TOF MS will probably only be available at selected facilities in the foreseeable future.
Whatever approach is taken, we feel that genotyping using non-gel-based technologies will have a bigger impact in the transfusion medicine diagnostics spectrum. However, it will not completely replace serology in the foreseeable future.

\section{References}

1 Avent ND: Recombinant technology in transfusion medicine. Curr Pharm Biotechnol 2000;1:117-135.

2 Dzik WH: Molecular diagnostics in transfusion medicine: the best is yet to come. Transfusion 1995; 35:183-185.

$\checkmark 3$ Westhoff CM, Sloan SR: Molecular genotyping in transfusion medicine. Clin Chem 2008;54:1948 1950.

4 Quill E: Medicine. Blood-matching goes genetic. Science 2008:319:1478-1479.

5 Ruan L, Pei B, Li Q: Multicolor real-time polymerase chain reaction genotyping of six human platelet antigens using displacing probes. Transfusion 2007:47:1637-1642.

6 Mohammadi T, Pietersz RN, VandenbrouckeGrauls CM, Savelkoul PH, Reesink HW: Detection of bacteria in platelet concentrates: comparison of broad-range real-time $16 \mathrm{~S}$ rDNA polymerase chain reaction and automated culturing. Transfusion 2005;45:731-736.

7 Skogen B, Bellissimo DB, Hessner MJ, Santoso S, Aster RH, Newman PJ, McFarland JG: Rapid determination of platelet alloantigen genotypes by polymerase chain reaction using allele-specific primers. Transfusion 1994;34:955-960.

8 Cardoso MS, Koerner K, Kubanek B: Mini-pool screening by nucleic acid testing for hepatitis B virus, hepatitis $\mathrm{C}$ virus, and HIV: preliminary results. Transfusion 1998:38:905-907.

9 Lefrere JJ, Danic B: Pictorial representation of transfusion over the years. Transfusion 2009; DOI 10.1111/j.1537-2995.2008.02068.x.

$>_{10}$ Lefrere JJ, Laperche S, Roudot-Thoraval F: Hepatitis $\mathrm{G}$ virus: a suitable marker of in vivo efficacy for pathogen inactivation. Vox Sang 2008;95:76-78.

11 Laperche S, Bouchardeau F, Thibault V, Pozzetto B, Vallet S, Rosenberg AR, Roque-Afonso AM, Gassin M, Stoll-Keller F, Trimoulet P, et al: Multicenter trials need to use the same assay for hepatitis $\mathrm{C}$ virus viral load determination. J Clin Microbiol 2007;45:3788-3790.

12 Lefrere JJ, Maniez-Montreuil M, Morel P, Defer C, Laperche S. Sécurité des produits sanguins labiles et parvovirus B1. Transfus Clin Biol 2006;13:235-241.

13 Lefrere JJ, Roudot-Thoraval F, Lunel F, Alain S, Chaix ML, Dussaix E, Gassin M, Izopet J, Pawlotsky JM, Payan C, et al: Expertise of French laboratories in detection, genotyping, and quantification of hepatitis C virus RNA in serum. J Clin Microbiol 2004;42:2027-2030.
14 Laperche S, Bouchardeau F, Maniez M, Beolet M, Elghouzzi MH, Lefrere JJ: Nucleic acid testing in blood donations reactive to hepatitis $\mathrm{C}$ virus antibody, but with an extremely low viral load. Vox Sang 2004;86:198.

15 Lardy NM, Otting N, van der Horst AR, Bontrop RE, de Waal LP: Full-length cDNA nucleotide sequence of a serologically undetectable HLA-DQA1 allele: HLA-DQA1*'LA'. Tissue Antigens 1997;50: 334-339.

16 Lardy NM, Otting N, van de Weerd MJ, van de Horst AR, Waal LP, Bontrop RE: Full-length cDNA nucleotide sequence of the HLA-B*4202 allele. Tissue Antigens 1997;50:83-84.

17 Kohnemann S, Sibbing U, Pfeiffer H, Hohoff C: A rapid mtDNA assay of 22 SNPs in one multiplex reaction increases the power of forensic testing in European Caucasians. Int J Legal Med 2008;122: 517-523.

18 Lessig R, Zoledziewska M, Fahr K, Edelmann J, Kostrzewa M, Dobosz T, Kleemann WJ: Y-SNPgenotyping - a new approach in forensic analysis. Forensic Sci Int 2005;154:128-136.

19 Bender K: SNaPshot for pharmacogenetics by minisequencing. Methods Mol Biol 2005;297:243-252.

20 Pati N, Schowinsky V, Kokanovic O, Magnuson V, Ghosh S:. A comparison between SNaPshot, pyrosequencing, and biplex invader SNP genotyping methods: accuracy, cost, and throughput. J Biochem Biophys Methods 2004;60:1-12.

21 Quintans B, Varez-Iglesias V, Salas A, Phillips C, Lareu MV, Carracedo A: Typing of mitochondrial DNA coding region SNPs of forensic and anthropological interest using $\mathrm{SNaPshot}$ minisequencing. Forensic Sci Int 2004;140:251-257.

22 Jungerius BJ, Veenendaal A, Van Oost BA, Te Pas MF, Groenen MA: Typing single-nucleotide polymorphisms using a gel-based sequencer: a new data analysis tool and suggestions for improved efficiency. Mol Biotechnol 2003;25:283-238.

23 Makridakis NM, Reichardt JK: Multiplex automated primer extension analysis: simultaneous genotyping of several polymorphisms. Biotechniques 2001:31:1374-1380

24 Wiesbauer M, Meierhofer D, Mayr JA, Sperl W, Paulweber B, Kofler B: Multiplex primer extension analysis for rapid detection of major European mitochondrial haplogroups. Electrophoresis 2006;27: 3864-3868.
25 Schena M, Shalon D, Davis RW, Brown PO: Quantitative monitoring of gene expression patterns with a complementary DNA microarray. Science 1995;270: 467-470.

26 Avent ND: Large-scale blood group genotyping: clinical implications. Br J Haematol 2009;144:3-13.

27 Avent ND, Martinez A, Flegel WA, Olsson ML, Scott ML, Nogues N, Pisacka M, Daniels G, van der SE, Muniz-Diaz E, et al: The BloodGen project: toward mass-scale comprehensive genotyping of blood donors in the European Union and beyond. Transfusion 2007;47(1 suppl):40S-46S.

28 Avent ND: Large scale blood group genotyping. Transfus Clin Biol 2007:14:10-15.

29 Li Y, Finning K, Daniels G, Hahn S, Zhong X, Holzgreve W: Noninvasive genotyping fetal Kell blood group (KEL1) using cell-free fetal DNA in maternal plasma by MALDI-TOF mass spectrometry. Prenat Diagn 2008;28:203-208.

30 Li Y, Hahn S, Holzgreve W: Recent developments in the detection of fetal single gene differences in maternal plasma and the role of size fractionation. Ann N Y Acad Sci 2006;1092:285-292.

31 Li Y, Wenzel F, Holzgreve W, Hahn S: Genotyping fetal paternally inherited SNPs by MALDI-TOF MS using cell-free fetal DNA in maternal plasma: influence of size fractionation. Electrophoresis 2006;27:3889-3896.

32 Garritsen HS, Fan AX, Bosse N, Hannig H, Kelsch R, Kroll H, Holzgreve W, Zhong XY: Matrix-assisted laser desorption/ionization time-of-flight mass spectrometry for genotyping of human platelet-specific antigens. Transfusion 2009;49:252-258.

33 Xiu-Cheng FA, Garritsen HS, Tarhouny SE, Morris M, Hahn S, Holzgreve W, Zhong XY: A rapid and accurate approach to identify single nucleotide polymorphisms of mitochondrial DNA using MALDI-TOF mass spectrometry. Clin Chem Lab Med 2008:46:299-305.

34 Tang K, Fu D, Kotter S, Cotter RJ, Cantor CR, Koster H: Matrix-assisted laser desorption/ionization mass spectrometry of immobilized duplex DNA probes. Nucleic Acids Res 1995;23:3126-3131.

-35 Tolson DA, Nicholson NH: Sequencing RNA by a combination of exonuclease digestion and uridine specific chemical cleavage using MALDI-TOF. Nucleic Acids Res 1998;26:446-451. 